University of Nebraska - Lincoln

DigitalCommons@University of Nebraska - Lincoln

To Improve the Academy

Professional and Organizational Development Network in Higher Education

1994

\title{
Complex Cooperative Learning Structures for College and University Courses
}

Philip G. Cottell Jr.

Barbara J. Millis

Follow this and additional works at: https://digitalcommons.unl.edu/podimproveacad

Part of the Higher Education Administration Commons

Cottell, Philip G. Jr. and Millis, Barbara J., "Complex Cooperative Learning Structures for College and University Courses" (1994). To Improve the Academy. 304.

https://digitalcommons.unl.edu/podimproveacad/304

This Article is brought to you for free and open access by the Professional and Organizational Development Network in Higher Education at DigitalCommons@University of Nebraska - Lincoln. It has been accepted for inclusion in To Improve the Academy by an authorized administrator of DigitalCommons@University of Nebraska - Lincoln. 


\section{Complex Cooperative Learning Structures for College and University Courses}

\section{Philip G. Cottell Jr.}

Miami University

\section{Barbara J. Millis}

University of Maryland University College

Instructors who have succeeded with cooperative learning in their classrooms may wish to move beyond the basics of structured small group work to more complex techniques which enable them to simultaneously meet multiple teaching objectives. This paper describes cooperative learning structures which not only help students learn course material but also enhance their learning skills. Instructors who use complex cooperative learning structures prompt their students to teach, to question, and to evaluate the learning of their peers.

Cooperative learning, a structured form of small group learning, has become increasingly accepted as an exemplary pedagogy at the college and university level. Grounded solidly in theory and research and endorsed by numerous classroom practitioners, cooperative learning

Portions of this paper have been adapted from Cottell, P.G. \& Millis B.J.,Instructor's resource guide [for] financial accounting: Information for decisions by Robert Ingram. Used with permission of South-Western Publishing Company. 
has proved to be a powerful classroom approach. Based on two key assumptions, positive interdependence (students have a vested reason to work together) and individual accountability (students cannot coast on the work of others: they are assessed individually), cooperative learning approaches consistently result in increased academic achievement. In addition to raising student achievement, cooperative learning can also have a dramatic impact on classroom climate because students involved in structured small group work usually develop a liking for the subject matter as well as a liking and respect for their fellow group members and classmates, regardless of their different ages, genders, or academic and ethnic backgrounds. Thus, cooperative learning assumes particular significance with the influx of nontraditional students into diverse classrooms.

These positive effects, plus many others, are supported by a solid research base. Cooperative learning is, according to Slavin (19891990), "one of the most thoroughly researched of all instructional methods" (p. 52). Johnson, Johnson, and Smith (1991b) conclude:

During the past 90 years, over 575 experimental and 100 correlational studies have been conducted by a wide variety of researchers in different decades with different age subjects, in different subject areas, and in different settings. . . Far more is known about the efficacy of cooperative learning than about lecturing, ... the use of technology, or almost any other facet of education. (p. 28)

Furthermore, although much of the research has been conducted at the K-12 level, Natasi and Clements (1991) conclude that the benefits of cooperative learning, described as "enhance[d] academic achievement and cognitive growth, motivation and positive attitudes toward learning, social competence, and interpersonal relations," (p. 111) seem to be universal. They emphasize that:

Cognitive-academic and social-emotional benefits have been reported for students from early elementary through college level, from diverse ethnic and cultural backgrounds, and having a wide range of ability levels. ... Furthermore, cooperative learning has been used effectively across a wide range of content areas, including mathematics, reading, language arts, social studies, and science. (p. 111) 
Thus, cooperative learning is also one of the most versatile educational strategies available. It complements virtually every pedagogy or approach known to promote effective teaching and learning: classroom research, the "Seven Principles for Good Practice in Undergraduate Education," stimulus materials, case studies, and problem-based curriculum. [Readers interested in detailed overviews of the research base for cooperative learning as it applies to higher education should consult Cooper, Prescott, Cook, Smith, Mueck, and Cuseo (1990) or Johnson, Johnson, and Smith (1991a).]

\section{Cooperative Learning Structures}

Cooperative learning is predicated on a nonelitist educational philosophy that values the growth and achievement of each student while recognizing the power of structured, supportive group work to further individual academic and personal potential. Structures are the content-free building blocks or tools that allow instructors to operationalize the philosophical basis of cooperative learning. Instructors insert their own content-specific information to create a classroom activity tied to course objectives. Thus, a brainstorming structure such as Roundtable used with specific course content-such as listing potential paper topics in a composition class or identifying significant issues facing Congress in a government class-results in an interactive, relevant classroom activity. Many structures used by a wide variety of teachers at all educational levels are effective in college and university courses. Because much of the early work on cooperative learning was done at the $\mathrm{K}-12$ level, the nomenclature, unfortunately, does not always suggest the rigor associated with postsecondary work. Faculty members committed to the principles of cooperative learning and the positive effects it will have on student achievement and affective behaviors, must simply remain open-minded and ignore the sometimes "cutesy" terminology. More productively, they might wish to substitute other terms when they use the structures with their students. For example, an effective activity called by Kagan (1992, p. 10:2-10:5) "Numbered Heads Together" and by Johnson, et al., (1991b, p. 4:16) "Problem Solving Lesson" sounds more palatable to college and university students when it is labeled "Structured Problem 
Solving." The point is: cooperative learning structures work, call them what one may.

A key advantage of cooperative learning rests in its versatility. Faculty developers urge their teaching colleagues to take risks in their teaching but not to rush precipitously into trying too much too soon. Those new to cooperative learning - sometimes those who have tried unsuccessfully other less structured forms of group work-should begin initially with the basic structures such as Think-Pair-Share (Kagan, 1992, pp. 11:2-11:3; Millis, 1990, p. 49; Cottell \& Millis, 1993, pp. 32-34). Faculty wishing to implement the complex cooperative learning structures that follow must have moved beyond casual, sporadic group work and committed themselves to establishing ongoing, long-term structured learning teams. Complex cooperative learning structures are supported by powerful secondary learning objectives that complement the primary content-related learning objectives. These secondary objectives prompt students to teach, to question, and to evaluate the learning of their peers. Complex cooperative learning structures enhance learning skills-writing and critical thinking skills in particular-as students cooperatively help one another assume responsibility for understanding course material.

\section{Structured Learning Teams}

Structured learning teams are the foundation upon which faculty build their cooperative learning classrooms. These permanent or semipermanent teams usually stay in place for a semester or half a semester. Using structured activities resulting in interactions within and among these teams, faculty can facilitate course learning. The course content is supported by the cooperative learning structures (see Figure One). Although some well-known advocates of cooperative learning such as Johnson, et al., (1991a, 1991b) recommend teams of three, most university and college level practitioners prefer heterogeneous groups of four or quads. Teams composed of four students offer several advantages: (a) quads are small enough that group members tend to stay attentive and on task. They can't hide or tune-out as might happen, for instance, in a group of eight or, more significantly, in a typical college classroom predicated on whole-class discussion; (b) quads are 
large enough to function smoothly when a team member is occasionally absent; and (c) quads lend themselves well to pair work, a powerful way to stimulate student achievement and critical thinking skills. If a class divides unevenly, it is easy to add a fifth member to several teams -often a student who may not be as strong as other team members, usually because of absenteeism but sometimes because of weak academic preparation. In such teams, of course, the students should never realize who the add-on might be.

\section{FIGURE 1}

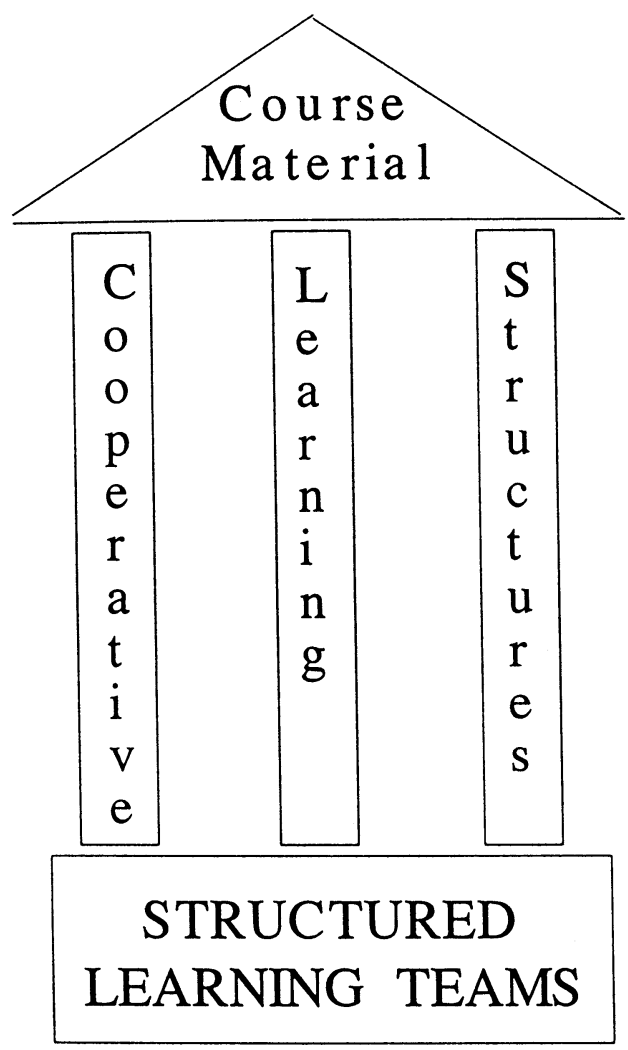

This figure is adapted from Cottell, P.G. \& Millis, B.J. (1994). Instructor's resource guide for financial accounting: Information for decisions by Robert Ingram. Cincinnati: South-Western. Adapted by permission. 
Structured learning teams, unlike looser collaborative groups, are supported by the instructor's intense, but nonintrusive involvement. Instructors initially provide a great deal of direction and carefully monitor group activities and dynamics. For example, the instructor carefully defines the roles of team members as well as the interactions within and among the teams. These interactions are never taken for granted: both instructors and students must insure that all team members are contributing to and benefitting from a productive learning environment.

Many instructors have discovered the value of a common deck of playing cards to organize teams, to facilitate cooperative directives, and to establish a sense of equity in calling on students. A different card issued to each student provides three crucial pieces of information. First, the rank of the card designates the team to which the student belongs; for example, the four students holding jacks become the structured learning team called the jacks, aces become aces, and so forth. (To build team camaraderie, instructors with classes under 60 may encourage teams to establish their own unique team names and identities.)

Second, the suit of the playing card identifies the role each student plays during a given class period and, unless otherwise specified, the role she or he plays for the cooperative activities. Rotating these roles helps build positive interdependence. This practice also discourages domination by one person, a problem common in less structured group work, and gives all students an opportunity to practice various social, communication, and leadership skills. The following defined roles work well in college and university courses:

- Leader - keeps the team on the assigned task and insures that all members of the team have the opportunity to learn, to participate, and to earn the respect of their teammates. Makes certain that all team members have mastered the required material during team activities.

- Monitor - sees that the team's work area is left the way that the team found it. Acts as the timekeeper for timed activities. In teams of four, assumes the role of any missing team member. In disciplines such as accounting where calculators are used for problemsolving, the Monitor operates the single team calculator, thus 
reinforcing positive interdependence. In teams of four, consults with other teams as directed.

- Recorder - keeps records of all team activities, including-if appropriate - the contributions of each member, in order to facilitate later assessment of individual accountability. If team folders are used, the recorder picks up the team folder and records attendance, homework, and/or quiz scores. Writes out solutions to problems or written assignments (for team use as notes or for submission to the instructor). Prepares transparencies for overhead projection when the team makes an oral presentation.

- Reporter - gives oral responses to the class about the team's activities or conclusions, often based on notes provided by the recorder.

- Wild Card (for teams of five) - acts as an assistant to the team leader. Assumes the role of any missing team member. Consults other teams for assistance when the instructor so indicates.

These assigned roles emphasize the value of all team members, thus raising individual self-esteem while simultaneously building group cohesion. Rotating the roles helps students learn and practice social teamwork skills, particularly for those students needing to cultivate them for the first time. This emphasis on rotating roles prepares all students for success not only in the cooperative learning classroom but also in the real world of adult life where teamwork is essential.

Third, the color of the suit indicates to the student his or her suit partner, that individual with whom the student will work when the instructor is using paired cooperative learning structures such as Think-Pair-Share or the Within-Team Jigsaw (discussed later).

Playing cards have other advantages as well. Because each student is readily identifiable, faculty can keep track of whom they have called on during the course of a semester. After a problem-solving activity, for example, the instructor might ask for summaries from the reporters (who might be the clubs on that given day) from three specific teams, the Jacks, the Aces, and the Fours. By keeping running notations of these respondents by their respective cards, instructors can be certain the next time that different individuals report out. This technique is also useful for whole-class discussions: eventually the instructor can 
be certain that everyone is called upon, not just those who are the quickest and most vociferous hand-raisers. As a variation, faculty can create a sense of fairness during whole-class discussions by randomly drawing a card from a second deck kept for that purpose.

Careful team formation can ensure the success of small groups. Cooperative learning advocates agree that heterogeneity enhances the effectiveness of structured group work. Cottell and Millis (1993; 1994) discuss cooperative learning structures useful for team formation. Many faculty members assign students to permanent or semipermanent structured learning teams or groups on the basis of data sheets they collect. In a junior-level children's literature class, for example, it might be useful to distribute students on the basis of their majors (making certain that an English major is assigned to each team); gender (adding a male to each team to ensure more balanced discussions); number of children in the household (encouraging the sharing of real world experiences); and ethnicity (reinforcing the value of multiple perspectives). In an accounting course, students might be assigned to structured learning teams on the basis of other criteria, such as intended area of emphasis (tax, auditing, financial or cost); academic achievement; prerequisites; previous work force experience, and so forth.

\section{Complex Cooperative Learning Structures}

Instructors who have succeeded with basic and advanced cooperative learning structures (see Cottell \& Millis, 1993; 1994) will find that adding complex structures to their teaching repertoire results in greater variety and heightened interest for students and for themselves. Most importantly, these complex structures promote higher order thinking skills and build more meaningful interpersonal relationships, ones that tend to keep students more involved academically. To use the complex cooperative learning structures, instructors will need to plan carefully each classroom activity. This planning will pay rich rewards in terms of deeper student comprehension of course material and appreciation of the learning process. When instructors share their methods and motives with students, they help students develop life- 
long skills of learning how to learn by emphasizing metacognitive skills.

Students actively involved with complex cooperative learning structures enhance their learning skills as they assume more responsibility for understanding the material. Instructors who use these structures assist students in developing skills of teaching, of questioning, and of evaluating the learning of others. Each of these activities results in greater student understanding. Each of them also promotes the two key elements of cooperative learning: positive interdependence and individual accountability. Although each of these complex structures stimulates multiple cognitive and affective outcomes-and that is their value - they are divided here according to their primary functions: teaching, questioning, and critiquing.

\section{Structures for Student Teaching}

Virtually all instructors recognize that through teaching they have learned more deeply the content and concepts of their discipline. Ironically, under a strict lecture format, conscientious instructors polishing and updating their presentations continue to add to their growing knowledge while their students, depending on a number of variables, may or may not come close to mastering the same body of material or developing the same analytical skills. Effective teaching results from "students teaching other students," according to McKeachie, Pintrich, Lin and Smith (1986, p. 63) who conducted an exhaustive review of the research literature on college and university learning. Through the cooperative learning structures discussed in this section, instructors give their students the rich opportunity to learn by teaching.

Jigsaw. Many disciplines contain complex, challenging problems involving multiple pieces of information necessary for a final, overall solution or overview. Such challenges are ideally suited for the cooperative learning structure, Jigsaw. Jigsaw, as its name implies, suggests that assignments can be split into manageable units that students can explore in depth. If students are in quads, then a task would be divided into four distinct but mutually related parts: In a Jigsaw these parts must add up to a meaningful whole. In this structure, each 
member of the structured learning team assumes responsibility for a specific part of a problem. For example, in a literature class, rather than having one team work superficially on four different character analyses, each student takes one particular character and with new teammates goes deeply into a close textual analysis. In an accounting class each student may analyze four separate business transactions which combine into a single financial report.

In Jigsaw, students temporarily leave their structured learning teams (home teams) to form expert learning teams which may be organized, for example, on the basis of the suits of playing cards. The student holding the heart from each of the groups meets with the other hearts in the class. Those holding spades, diamonds, and clubs form similar expert teams. Figure Two illustrates how a class of 20 can be

\section{FIGURE 2}

Step 1. Organize cooperative learning groups by using playing card ranks similar to the following:

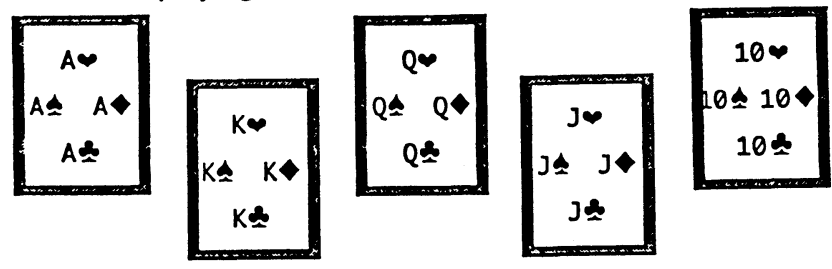

Step 2. Use suits (such as spades) to form expert learning teams of five members as follows:
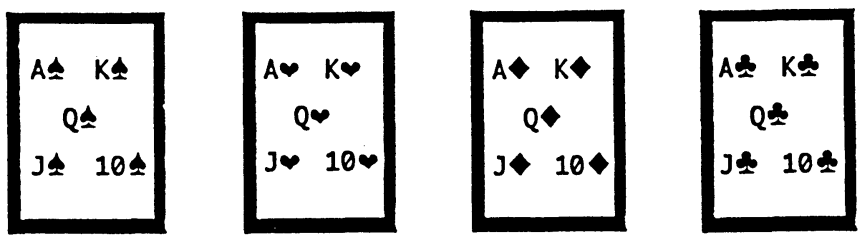

This figure is adapted from Cottell, P.G. \& Millis, B.J. (1994). Instructor's resource guide for financial accounting: Information for decisions. Cincinnati: South-Westem. Adapted by permission. 
quickly transformed from five structured learning teams into four expert learning teams with five members, one from each of the original groups. If classes are larger, students can form two or more expert teams to work on the same piece of the puzzle. If the original structured team consists of five members rather than four, then two students pair and work as a unit in their expert team and then they return to their original team.

In expert learning teams, the students focus on mastering, solving, or analyzing their part of the problem or issue. They also discuss and develop strategies to teach the solution-and the process of deriving it - to the other members of their structured learning (home) teams once they have rejoined them. Students must recognize that for Jigsaw to succeed, no one should leave his or her expert team without the ability to explain clearly - to teach - the process and procedures just developed. Instructors move among the various expert teams monitoring their progress and checking to see that all students are involved. After the prescribed time, the students return to their structured learning teams where the expert students in turn teach their respective piece of the puzzle.

Instructors must work conscientiously to structure the team activities, the physical logistics, and the time frame of a Jigsaw. This is not a structure that should be attempted by relative newcomers to cooperative learning, particularly if large classes are involved. Students, too, must be coached to understand both the mechanics and the value of Jigsaw. Instructors must guard, for example, against student tendencies to get off task. Instructors must clearly communicate to students that more is at stake than finding the right answer. The ability to teach fellow teammates-and hence master and retain important materials and develop analytical skills-lies at the crux of Jigsaw. Thus, a properly executed Jigsaw provides benefits that far outweigh its costs in terms of time and effort. For one thing, like most complex structures, Jigsaw reinforces the most basic tenets of cooperative learning. Positive interdependence is fostered by the fact that students must work together and teach one another in order to get the big picture, all of the information and skills they will need to understand the entire problem or academic task. At the same time, individual accountability is reinforced by the fact that students must learn all the 
information, not just their own portion, because they are tested individually. The fact that students interact within two different groups reinforces the value of heterogeneity in bringing multiple perspectives to a given problem. The positive interactions that result from these brief, but intense, encounters in the expert groups help to develop the skills students will need in the real world. The fact that expert teams have the responsibility of making certain that all members can successfully teach the materials/conclusions also reinforces the important concept of group processing and accountability.

Within-Team Jigsaw. In Within-Team Jigsaw, expert learning teams consist of a pair formed within the structured learning team. Any fifth member (sometimes identified with a wild card or joker) joins a pair to form a triad. If instructors are using playing cards to identify team roles, the suits can be used for pairing, black suits forming one pair and red suits the other. These suit partners function as smaller expert learning teams, similar in function to those formed in Jigsaw.

Instructors who use Think-Pair-Square (Kagan, 1992, p. 11:3) should explain the difference between that structure and Within-Team Jigsaw. In Think-Pair-Square, students simultaneously work on the same task and verify their answers in the structured learning team. In the more complex Within-Team Jigsaw, suit partners work on two distinct parts of a puzzle or other academic task. Their task in the structured learning team is to put together the pieces to arrive at a solution and to teach other members of the structured learning team their portion of the problem.

Within-Team Jigsaw is easier to implement than Jigsaw, primarily because it does not involve physical movement into new teams. Its disadvantage lies in the fact that the puzzle or academic task can have only two pieces. Within-Team Jigsaw, however, can be a creative, efficient way to ensure content mastery and build higher order thinking skills.

\section{Structures for Student Questioning}

Faculty frequently encounter dualistic thinkers who assume there are absolute answers to questions, i.e., those in stages one through 
three in Perry's (1970) scheme or in the early stages of the hierarchy described by Belenky, Clinchy, Goldberger, and Tarule (1986).

These students need to be encouraged to move beyond these simplistic levels of thinking. Often instructors assume that animated whole-class discussions will lead students to reflect on multiple viewpoints and discard outmoded ways of thinking. Such discussions provide useful class interactions when used occasionally; but, for many reasons, they cannot be the sole vehicle for challenging student assumptions and encouraging higher order thinking skills. For one thing, whole-class discussions are unpredictable. Successful discussions depend on many variables: the instructor's experience and skill in managing such exchanges; the constellation of personalities enrolled in the class and their reactions to instructor or student contributions; the academic preparation and real life experiences of the participants; and the nature of the topic itself. Furthermore, within a whole class exchange, many students are able to hide as nonparticipants, behavior prompted by innate shyness, by lack of comfort or confidence with confrontations before large audiences, by lack of preparation, or by simple apathy.

Cooperative learning structures enable instructors to help students learn to question the truth of assumptions or propositions, but they do so within a highly structured environment with far fewer variables and hence less unpredictability. A supportive cooperative learning climate contrasts sharply, for example, with a classroom arena where the instructor relies on the stimulating Socratic method of challenging students with a series of thought-provoking questions. Both techniques are valuable, and savvy college instructors use both. But the value of cooperative learning questioning lies not only in the comfortable climate which encourages participation but more importantly in the fact that the students, not the instructors, pose the challenging questions. Structured Controversy and Guided Reciprocal Peer Questioning are stimulating ways to develop higher order thinking skills within a supportive environment. Ideally, classrooms provide the combination of challenge and support needed for student success (Widick, Knefelkamp, \& Parker, 1975).

Structured Controversy. Structured Controversy-called Academic Controversy by Johnson, et al., (1991a)—develops critical 
thinking skills by compelling students to examine issues for which there are no right answers. As in Within-Team Jigsaw, students initially work with partners in their structured learning teams, such as suit partners if playing cards are used. In preparation for the activity, instructors identify a controversial topic that lends itself well to two opposing viewpoints and gather material - such as articles, monographs, or book chapters - that support either or both sides. If this structure is to be used for a long-range project, then the students themselves - with coaching - can identify and accumulate the material. Each pair within the structured learning team takes one side of the controversial issue. In the first of five phases of Structured Controversy, students research and review the academic materials provided or gathered, and discuss their side of the issue. They synthesize and organize their findings and prepare to advocate and defend their positions.

In the second phase, the two pairs alternatively present their side of the issue, giving full rationales and explanations for their stance. The other pair listens attentively, keeping in mind that during the next phase they will be challenging the points they hear and also defending their own positions.

In this third phase, during a general discussion all four students seek to become fully informed about both sides of the issue and begin to weigh critical arguments in favor of both. Instructors should stress that the students' purpose should be to become more informed about the issue rather than to win debates. They should use skillful questioning techniques to draw out their fellow teammates and to encourage everyone to examine deeply all sides of the issue. The result of the discussion, which must be conducted and carefully monitored according to established team or class norms for productive behavior and interaction, is often intellectual disequilibrium and uncertainty. This phase of the activity is particularly important because Brookfield (1987) and others have emphasized that critical thinking depends on identifying and challenging assumptions and subsequently exploring and conceptualizing alternatives. Curiosity prompted by this discussion often leads to a search for additional information.

If the process is carried through its full five phases, then during this next fourth step, students reverse their positions and each pair 
argues forcefully for the opposing viewpoint. Building on what they have heard earlier and what they have come to learn through their own research and the subsequent team discussion, each pair or dyad presents the best possible case.

In the fifth and final phase, the team works together to synthesize its findings and prepare a group report. This final review should reflect the best information and critical reasoning from both sides. To insure individual accountability, the instructor may wish to administer an examination over the issue that students will take independently.

Guided Reciprocal Peer Questioning. Instructors wishing to encourage critical thinking skills and higher-order conceptualizing will find Guided Reciprocal Peer Questioning a particularly apt structure. Developed and researched by King $(1992 ; 1990)$, this structure helps

\section{FIGURE 3 \\ Generic Question Stems}

- What is the main idea of...?

What if...?

How does... affect...?

What is the meaning of...?

What is a new example of...?

Explain why...

Explain how...

How does this relate to what I've learned before?

What conclusions can I draw about...?

What is the difference between... and...?

How are... and...similar?

How would I use...to...?

What are the strengths and weaknesses of...?

What is the best....and why...?

This figure appears in Critical thinking, interactive learning and technology by Alison King, page 162, Arthur Andersen and Co., 1992. Reprinted with permission. 
students to generate content-specific questions which can then be answered within the structured learning team.

In a lecture-related version of this activity, instructors conduct a short lecture on a course-related topic. Following the lecture, instructors provide students with a set of generic question stems to use as a guide for formulating their own specific questions about the lecture content. Figure Three provides a list of these generic question stems. Some questions, such as "What is the difference between...and...?," will appeal more to dualistic thinkers. Other questions, such as "What are the strengths and weaknesses of...?," are more appropriate for the more advanced relativistic thinkers. Instructors will also recognize that the generic stems challenge students to formulate questions on all six levels of Bloom's cognitive taxonomy: knowledge, comprehension, application, analysis, synthesis, and evaluation.

Instructors provide individual students with a set time-five minutes or less - to use the generic stems to prepare two or three specific, thought-provoking questions on the lecture they have just heard. Students do not need to be able to answer the questions they formulate: their purpose is to generate discussion. As students formulate questions, they tend to identify the relevant lecture concepts, elaborate on those ideas, and think about how the ideas are connected to each other and their own prior knowledge and experiences.

After the allotted time has elapsed, the students then query one another in their structured learning teams. A designated team member asks the quad to respond to one of the specific questions he or she has written. Since the questions do not have a single right answer, reflective discussion follows. Each student in turn offers a question, using a different question stem, for the team to discuss. Everyone should have an opportunity to pose at least one question: the leader should be careful that there is equitable participation both in the discussion and in the questions shared.

In designing a Guided Reciprocal Peer Questioning activity, instructors should schedule the time elements carefully. Time should be allotted, for example, for whole class discussion at the end of the exercise. Here the students can share insights, concrete examples, and particularly cogent explanations that arose in their group work. The instructor, who has been moving among the groups during their 
discussion period, also has an opportunity to elaborate on any cloudy points or to clear up any misconceptions about the topic under study. Closure is extremely important in cooperative classrooms. Students should not feel that instructors have abandoned their teaching responsibilities. The generic question stems are useful in many other contexts, such as reviewing chapter assignments or preparing for upcoming quizzes or examinations.

\section{Structures for Student Critiquing}

The structures for student critiquing contain rich learning opportunities for students. In each case, students formulate questions, suggest answers to the questions of others, and evaluate the responses generated by peers. Students therefore learn not only important concepts about the discipline but also learn about the learning and teaching process itself. The structures prompt students to move into the higher levels of Bloom's taxonomy, particularly evaluation. Such approaches also allow the instructor to front-load material, building in incentives for students to actually master assigned reading material, including textbook chapters. Too often in traditional classrooms instructors are disappointed that students do not come to class prepared to discussthrough whole-class methods where students typically can hide-assigned material. In teaching methods such as team learning, developed by Michaelson $(1983 ; 1992)$ to cope with large classes, students have strong incentives to master material before they take individual and group tests. During the group test and a subsequent appeal process, students actively teach, challenge, and critique one another within the relatively safe confines of a structured learning team. Similarly, the two cooperative structures that follow enable students to experience meaningful, collaborative, intellectual dialogues.

Send/Pass-a-Problem. The Send/Pass-a-Problem structure gives students the opportunity to identify or focus on their own issues or problems and to experience the problem solving process in the context of community. The exact source of this structure is unclear, but a version of it was generated by the Howard County, Maryland Staff Development Center in 1989, inspired by Kagan's (1992) high con- 
sensus oriented Send-a-Problem structure using rotating flash cards for content review.

To initiate Send/Pass-a-Problem, instructors must have at hand a list of problems or issues for which the structured learning teams can generate solutions. These issues can be identified by the instructor, but students have far more investment in the activity if they have generated the possible topics themselves while in their teams. The issues typically are discussed at the same class meeting, but an alternative, particularly attractive for faculty teaching 50-minute classes, is to have students generate the problem topics during one session (perhaps using a brainstorming structure such as Roundtable) and then pose them for discussion at the ensuing session.

The steps in Send/Pass-a-Problem, once each team identifies the issue or problem it will address, are fairly straightforward: (a) Each team discusses its particular problem and generates within the given time frame as many solutions as possible; the solutions, recorded on a sheet of paper, are placed in a folder (an envelope will also work well) with the problem addressed clearly noted on the outside. (b) The folders are passed clockwise to another team who does not open the folder. That team, seeing only the problem identification but not the solutions generated by the previous team, follows an identical procedure and brainstorms solutions, placing their recorded conclusions in the folder or envelope. (c) The folders are passed a third time, but in this case, the team opens the folder and reviews the ideas/solutions generated by the other two teams. They are able to add additional ideas of their own, but their primary task is to identify the two most viable solutions to the given problem or issue. Instructors may want them to use a star or a check to identify these solutions. (d) Group reports provide useful closure. The reporters announce the issue their team discussed, the two solutions they have chosen, and, if desired, the team that suggested them. The creativity and multiplicity of solutions reinforces the value of structured teamwork.

Send/Pass-a-Problem is an extremely variable structure. It can be used successfully as a brainstorming activity with each team blitzing through as many solutions as possible within a narrow time limit, such as three minutes for each step. Most often, however, the structure is 
used as a vehicle for meaningful discussion, thoughtful synthesis, and creative problem solving.

Instructors will find Send/Pass-a-Problem useful for reviews, particularly prior to the final examination. To initiate a review, the instructor brings to class old quiz problems or exercises attached to folders or envelopes. The quiz problems or essay issues obviously reflect topics that have been covered during the semester that may appear on the final examination. Each structured learning team receives one of the envelopes.

The instructor tells the students that their team will have 10 minutes to solve the quiz problem or generate a topical essay as a closed-book exercise. When the time has expired, the students put their solution inside the folder or envelope and pass the packet clock-wise to the neighboring team. Students in the next group solve the same problem or address the same essay topic without looking into the envelope and add their solution at the end of 10 minutes. Depending on the length of the class period, this procedure may be repeated up to five times so that each group solves five problems or addresses five essay questions.

On the final pass, the instructor tells the students to retrieve all the solutions in the envelope and select the best solution, taking into account not only the right answer but also the neatness of form and presentation or the organizational and persuasive strengths of the essays. Group reporters in turn designate the problem, briefly explain the best approach for solving it, and identify, if desired, the group that presented it. A similar procedure can be used as a review over assigned material such as a particularly complex chapter.

Dyadic Essay Confrontations (DEC). In addition to building student understanding of course material concepts and the learning process, DEC allows instructors to incorporate meaningful writing assignments into their courses. Instructors will find DEC particularly valuable for students more advanced in the learning process. Probably its most important use is to insure that students read and understand the assigned reading material, thereby freeing class time for mastery and processing activities.

Developed by Sherman (1991), in DEC the instructor assigns readings, such as a chapter from the text or a chapter complemented 
by a primary source or other selected readings. Students are responsible outside of class for the following: (a) reading and reflecting on the assigned material; (b) formulating an integrative essay question, one which encourages comparisons between the current material and material previously covered; (c) preparing a model response to their own question which is no longer than one page, single-spaced; (d) bringing to class a copy of their essay question and on a separate page their model answer.

During class time, students are responsible for the following: (e) exchanging essay questions with a student with whom they are randomly paired; (f) writing a spontaneous essay in response to the question they receive from their partner; $(\mathrm{g})$ reading and commenting on both the model answer to the question they received and on the spontaneous answer provided by a classmate to the essay question they formulated, looking in each case for divergent and convergent ideas; and (h) participating - if time permits - in a general discussion of the topic.

The essays over the assigned material - both the out-of-class open-book paper and the in-class closed-book spontaneous essay are evaluated, but their weight depends on the overall grading criteria. To lighten the paper grading load, the essays, if they are of sufficient quality, may be assigned points counting toward the final grade rather than assigned a specific letter grade, a form of mastery learning. DEC can be used as a series of ongoing assignments over the course of a semester to ensure mastery of the course content, particularly as it relates to assigned readings in textbooks. Students who have written two essays and read two others over each chapter in a textbook, particularly if connections to lecture topics and other outside materials are emphasized, will retain far more material than those who have merely read the chapters (or not!) and then heard a lecturer expound on them.

As should be obvious, a complex and yet highly focused structure such as DEC has enormous value for university teaching and learning. With the virtue of versatility, it can promote higher order thinking skills; focus students on outside assignments so that time is available for interactive group work rather than for lectures designed to cover the content; foster student-student interdependence, resulting in re- 
spect for diverse opinions; and reinforce the value of peer learning. It also complements writing across the curriculum efforts.

As a modification of DEC, instructors may have students compose a problem and a suggested solution. Students participating in the problem-writing portion of this structure glean a greater understanding of the underlying course material concepts than they do by simply working prefabricated problems from a book. Moreover, discussions of the student-generated problems and solutions are more meaningful than discussions of solutions asked by unknown textbook or case authors.

\section{Summary and Conclusion}

With the increasing demands for accountability in teaching, faculty must adopt more innovative teaching strategies, effective ones predicated on active learning, cooperation, and respect for individual learning styles. Increasingly, both researchers and classroom practitioners are recommending cooperative learning. Structured in-class activities are a hallmark of cooperative learning, probably a welcome sign for those who fear group work will be considered a loose teaching philosophy practiced by lazy instructors intent on winging it.

Far from being a loose teaching philosophy, because of its structured and accountable approach, cooperative learning demands careful preparation and well-organized, well-conducted, relevant classroom activities and assignments. As Cooper, et al., (1990) cautions, "The three most important things in setting up a Cooperative Learning classroom are Structure, Structure, and Structure" (p. 1).

Complex structures require faculty members to make a key commitment toward student learning. They must feel comfortable with placing students in permanent or semipermanent learning teams, and they must be willing and eager to monitor their progress. They must also be innovators who can integrate these structures into their course objectives to create meaningful, student-centered classroom activities. The payoffs in student learning, retention, liking for subject matter and classmates - as one might expect - will be enormous. Research supports this and countless practitioners will testify to the power of this approach. The good news for faculty is that their tasks become 
easier as they and their students become more accustomed to structures such as Guided Reciprocal Peer Questioning, Send/Pass-a-Problem, or DEC.

Many faculty members at a variety of institutions have successfully embraced cooperative learning techniques. Few ever return to teaching as usual. Such an approach will no longer suffice in a global, connected world where new technologies demand lifelong learning and diverse societies require the ability to work and live harmoniously with many different people. As Ekroth (1990, p. 1) notes, "Today's professors are challenged to teach a student population increasingly diverse in age, levels of academic preparation, styles of learning, and cultural background. Professors are now expected not only to "cover the material' but also to help students to think critically, write skillfully, and speak competently."

Faculty members using complex cooperative learning structures within the context of their philosophical framework and the logistics of effective day-to-day classroom management techniques will discover new joys in teaching. Their students will discover new joys in learning.

\section{References}

Belenky, M. F., Clinchy, B. M., Goldberger, N. R., \& Tarule, J. M. (1986). Women's ways of knowing: The development of self, voice, and mind. New York: Basic Books.

Brookfield, S. D. (1987). Developing critical thinkers: Challenging adults to explore alternative ways of thinking and acting. San Francisco: Jossey-Bass.

Cooper, J. L., Prescott, S., Cook, L., Smith, Mueck, R. R., \& Cuseo, J. (1990). Cooperative learning and college instruction: Effective use of student learning teams. Long Beach, CA: The California State University Foundation.

Cottell, P. G., \& Millis, B. J. (1993). Cooperative learning structures in the instruction of accounting, Issues in Accounting Education, 8(1), 40-59.

Cottell, P. G., \& Millis, B. J. (1994). Instructor's resource guide [for] financial accounting: Information for decisions by Robert Ingram. Cincinnati: South-Western.

Ekroth, L. (1990, Winter-Spring). Why professors don't change. In L. Ekroth (Ed.), Teaching Excellence: Toward the Best in the Academy, Stillwater, OK: Professional and Organizational Development Network in Higher Education.

Johnson, D. W., Johnson, R. T., Smith, K. A. (1991a). Active learning: Cooperation in the college classroom. Edina, MN: Interaction Book Company. 
Johnson, D. W., Johnson, R. T., \& Smith, K. A. (1991b). Cooperative learning: Increasing college faculty instructional productivity (ASHE-ERIC Higher Education Report No. 4). Washington, D. C.: The George Washington University, School of Education and Human Development.

Kagan, S. (1992). Cooperative Learning. San Juan Capistrano, CA: Resources for Teachers.

King, A. (1990). Enhancing peer interaction and learning in the classroom through reciprocal questioning. American Educational Research Journah, 27(4), 664-687.

King, A. (1992). Promoting active learning and collaborative learning in business administration classes. In T. J. Frecka (ed.), Critical thinking, interactive learning and technology: Reaching for excellence in business education (pp. 158-173). Chicago, IL: Arthur Andersen Foundation.

McKeachie, W. J., Pintrich, P. R., Lin, Y., \& Smith, D. A. (1986). Teaching and learning in the college classroom: $A$ review of the research literature. Ann Arbor: The University of Michigan.

Michaelson, L. K. (1983). Team learning in large classes. In C. Bouton \& R. Y. Garth (eds.), Learning in Groups (pp. 13-22). New Directions for Teaching and Learning, No. 14. San Francisco: Jossey-Bass.

Michaelson, L. K. (1992). Team Learning: A comprehensive approach for harnessing the power of small groups in higher education. In D. H. Wulff \& J. D. Nyquist (eds.), To Improve the Academy: Resources for Faculty, Instructional, and Organizational Development, 11 (pp. 107-122). The Professional and Organizational Development Network in Higher Education, Stillwater, OK: New Forum Press, Inc.

Millis, B. (1990). Helping faculty build learning communities through cooperative groups. In L. Hilsen (ed.), To Improve the Academy: Resources for Faculty, Instructional, and Organizational Development, 10 (pp. 43-58). The Professional and Organizational Development Network in Higher Education, Stillwater, OK: New Forums Press, Inc.

Natasi, B. K., \& Clements, D. H. (1991). Research on cooperative learning: Implications for practice. School Psychology Review, 20(1), 110-131.

Perry, W. (1970). Forms of intellectual and ethical development in the college years: $A$ scheme. New York: Holt, Rinehart, and Winston.

Sherman, L. W. (1991, April). Cooperative learning in post-secondary education: Implications from social psychology for active learning experiences. Paper presented at the American Educational Research Association, Chicago, IL.

Slavin, R. E. (1989-1990). Research on cooperative learning: Consensus and controversy. Educational Leadership, 13, 21-39.

Widick, C., Knelfelkamp, L., \& Parker, C., (1975). The counselor as developmental instructor. Counselor Education and Supervision, 14, 286-296. 